\title{
Synthesis of New Derivatives of Resveratrol and to Explore its Potential Health Benefits
}

\author{
E. F. AL-JUMAILY* ${ }^{*}$ Z. A. SHAFIQ ${ }^{\mathrm{a}}$ and R. I. AL-BAYATI ${ }^{\mathrm{a}}$ \\ *Institute of Genetic Engineering \& Biotechnology for Postgraduate Studies, \\ University of Baghdad, Iraq

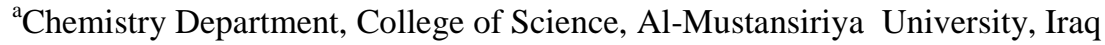 \\ samgen992003@yahoo.com
}

Received 15 June 2012 / Accepted 8 July 2012

\begin{abstract}
The aim of this study was extracting and purifying resveratrol from skin black grapevine. The synthesis of new derivatives from purified resveratrol was employed through out a series of reactions. The synthesized compounds are: $(E)-2,2$ '-(5-(4-(carboxymethoxy)styryl)-1,3-phenylene) bis (oxy) diacetic acid (derivative 1); (E)- 5-(4-(3-chloropropanyloxy)styryl)-1,3-phenylene) bis(3-chloropropanoate (derivative 2); 5-(4-(4-hydrazinylbutanoyloxy) styryl)-1,3-phenylenebis(4-hydrazinylbutanoate) (derivative 3) and 5-(4-(4-(2-(benzo[d]thiazol-2-yl)hydrazinyl) butanoyloxy) styryl)-1,3phenylene bis(4-(2-(benzo[d]thiazol-2-yl) hydrazinyl)butanoate) (derivative 4) respectively. The synthesized compounds were studied for exploring potential health benefits.
\end{abstract}

Keywords: Reveratrol, Reveratrol derivatives, Synthesis, Health Benefits

\section{Introduction}

Resveratrol belongs to a class of polyphenolic compound called stilbene. It is a non flavonoid and non steroidal phytochemical estrogenic agent ${ }^{1}$. Some types of plants produce resveratrol and other stilbenes in response to stress, injury, fungal infection and ultraviolet radiation ${ }^{2}$. Resveratrol is a fat-soluble compound that occurs in trans and cis configuration. Both cis- and trans-resveratrol also occur as glucosides (bound to a glucose molecule). Resveratrol-3-O-beta-glucoside is also called piceid (Figure 1).

3,5,4'-Trihydroxy-trans-stilbene is a stilbenoid, natural phenol and a phytoalexin produced naturally by different plants when under attack by pathogens such as bacteria or fungi. The effects of resveratrol are currently a topic of various animal and human studies. Its effects on the lifespan of many model organisms remain controversial, with uncertain effects in fruit flies, nematode worms and short-lived fish ${ }^{3}$. In the only actual human trial, extremely high doses (3-5 g) of resveratrol, in a proprietary formulation designed to enhance its bioavailability, significantly lowered blood sugar ${ }^{4}$. Despite the mainstream press alleging resveratrol's anti-aging effects 5 . There was no accepted data to form a scientific basis for the 
application of these claims to mammals. Resveratrol found in the skin of red grapes and other fruits. Red wine contains a high level of it and some scientists believe it is one of the factors behind the French Paradox, while others believe proanthocyanidin is the active ingredient involved. Resveratrol has also been produced by chemical synthesizer by biotechnological synthesis (metabolic engineered microorganisms) and sold as a nutritional supplement derived primarily from Japanese knotweed ${ }^{6}$. cis-Resveratrol found in wine but at the lower level than the trans isomer. The trans - to - cis resveratrol conversion occurs when the wine is exposed to light and oxygen ${ }^{7}$. The potential for resveratrol to inhibit the development of cancer and extend lifespan in cell culture and animal models have continued to generate scientific interest ${ }^{8}$. The aim of this study was synthesizing new compounds derived from resveratrol phytochemical constituent, evaluating the physicochemical characteristics of these compounds.

\section{Experimental}

Local black grapes cultivated in Iraqi were collected from the local market and classified as Vitis vinifera by the herbarium of the Biology Department, College of Science, Baghdad University. The skin was separated from the fruit to be then kept in a dark, cool place; all steps were done away from direct light and extensive stress that led to oxidation of the plant extract. About $500 \mathrm{~g}$ of fresh skin grapes were shaken with 2.5 litters' $99.9 \%$ ethyl acetate in cool dark place for $72 \mathrm{~h}$. The extract was filtered and the filtrate was dried at $30-40{ }^{\circ} \mathrm{C}$ by a rotary evaporator to get $1 / 10$ (one tenth) its original volume stored at $-20^{\circ} \mathrm{C}$. The functional groups i.e. double bond and phenolic group present in the resveratrol was tested by standard methods ${ }^{9}$. The aromaticity was analyzed using Friedel Crafts method ${ }^{10}$. Melting point was taken using melting point apparatus (Glascoo, UK). Resveratrol melting point range was $252-255^{\circ} \mathrm{C}$.

\section{Isolation and purification of resveratrol}

Isolation of resveratrol was carried out using HPLC-FTIR. Pure reveratrol was detected by FTIR

\section{HPLC method}

According to Jeandent et al. ${ }^{11}$, the following configuration was followed for HPLC method. Column: C18 - Reverse phase.

Mobile phase: acetonitrile: water, 60:40.

Flow rate: $0.6 \mathrm{~mL} / \mathrm{min}$.

Standard concentration: $0.6 \mathrm{mg} / \mathrm{mL}$ (exposed to sun light).

Sample concentration: $0.6 \mathrm{mg} / \mathrm{mL}$.

Wavelength: $307 \mathrm{~nm}$ for trans and $280 \mathrm{~nm}$ for cis isomers.

\section{Preparation of resveratrol derivatives}

\section{(E)-2, 2'-(5-(4-(Carboxymethoxy)styryl)-1,3-phenylene)bis (oxy) diacetic acid (1)}

$0.25 \mathrm{~g}$ of Resveratrol was dissolved in dry benzene $(20 \mathrm{~mL})$ with few drops of triethylamine and then chloroacetic acid (0.002 mole in dry benzene) was added drop wise. The reaction mixture was stirred then refluxes for 2 hours the precipitate was filtrated and dried.

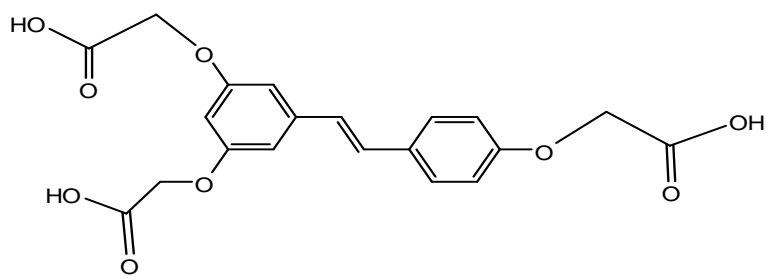


(E)-(5-(4-(3-Chloropropanyloxy)styryl)-1,3-phenylene)bis(3-chloropropanoate) (2)

$2 \mathrm{~g}$ of Compound 1 was dissolved in dry benzene $(20 \mathrm{~mL})$ with few drops of triethylamine and then 3-chloropropionyl chloride ( 0.05 mole in dry benzene) was added drop wise. The reaction was stirred in an ice bath, then reflux for 6 hours the solvent was removed, and the precipitate was filtrated and dried.

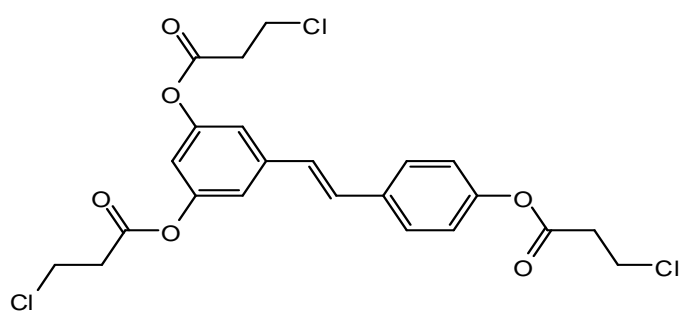

5-(4-(4-Hydrazinylbutanoyloxy)styryl)-1,3-phenylene bis(4-hydrazinylbutanoate) (3)

$3 \mathrm{~g}$ of Compound 2 (0.006 mole) was dissolved in absolute ethanol $(50 \mathrm{~mL})$ and then hydrazine hydrate $(0.02$ mole) was added, then reflux for $7 \mathrm{~h}$ the solvent was removed by rotatory evaporator and the precipitate was filtrated and dried.

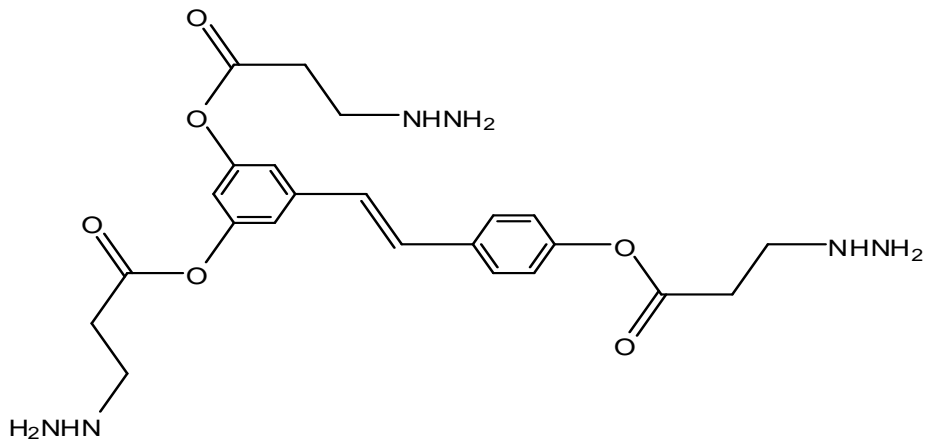

5-(4-(4-(2-(Benzo [d] thiazol-2-yl) hydrazinyl) butanoyloxy)styryl)-1,3-phenylene bis(4-(2-(benzo[d]thiazol-2-yl)hydrazinyl)butanoate) (4)

$1.6 \mathrm{~g}$ of Compound 2 (0.003 mole) was dissolved in absolute ethanol $(50 \mathrm{~mL})$ and then $1.58 \mathrm{~g}$ 2-mercptobenzothiazol (0.0096 moles) was added, then reflux for $8 \mathrm{~h}$ the solvent was removed and the precipitates were filtrated and dried .

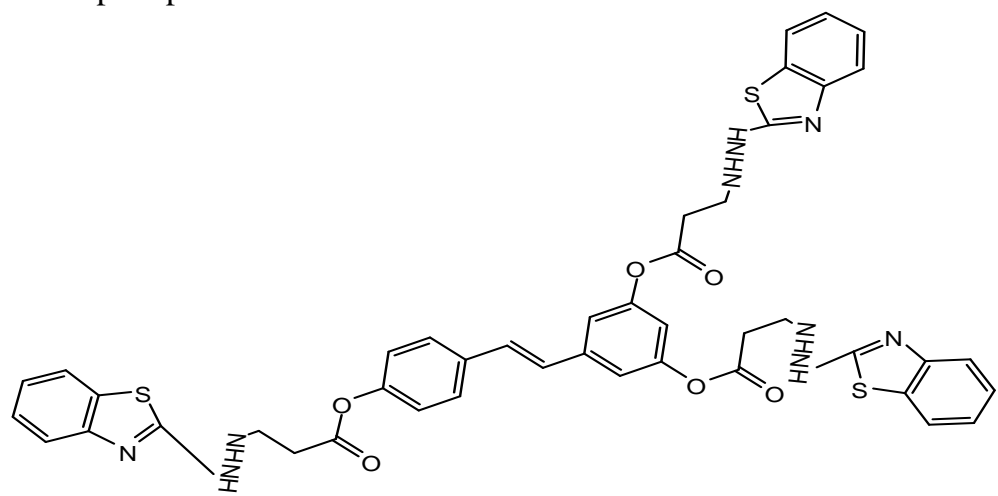




\section{Results and Discussion}

Fresh black grape skin 500 g was extracted with ethyl acetate and an organic solvent (diethyl ether) then resveratrol separation with liquid-solid adsorption chromatographic technique by silica gel open column yielded partially purified resveratrol to be eluted and isolated as pure resveratrol by P.T.L.C method. The yield of the pure crystals is about $35 \mathrm{mg}$ for the $500 \mathrm{~g}$ grape skin used, there may be some lose during processing of extraction, since the naturally occurring trans-resveratrol easily oxidized and converted to the cis- configuration by light and with the heat, heavy metals and atmospheric oxygen ${ }^{12}$. The fresh skin of black grapes (Vitis vinifera) is rich with a non-flavonoid polyphenol, resveratrol and each gram of fresh grape skin contain 50-100 microgram of pure resveratrol ${ }^{13}$.

The procedure for extraction and purification was concluded from different studies. All the processes have been carried out in the dark. The grape skin was extracted with $80 \%$ ethanol ${ }^{14}$. The optimum conditions for the extraction of resveratrol are $80 \%$ ethanol for 30 min at $60^{\circ} \mathrm{C}$ to prevent enzymic oxidation. The trans and cis resveratrol $O$-D-glycoside (piceid) were acid hydrolyzed with $10 \%$ conc. $\mathrm{HCl}$ on a water bath for $10-30 \mathrm{~min}^{15}$. The free aglycone moiety is water insoluble and can be easily taken up with organic solvent such as chloroform ${ }^{1}$. It was done using silica gel G60 column chromatography technique with mobile phase benzene: methanol: acetic acid, 20:4:1 to elute fractions according to their affinity to stationary phase. The resultant fractions that give positive ferric chloride test $1 \%$ solution. Since the grape skin contains numerous amounts of chemical compounds, the extract cleaning up was necessary by liquid-liquid partition technique for separation compounds according to the different distribution coefficients and the solvent affinity to solutes $^{16}$. Ethyl acetate is a good solvent for resveratrol taking up as viewed in many studies $^{17}$. Resveratrol (partial and pure) was tested for general phenolic tests (Table 1).

All the resultant chromatogram for purified resveratrol is shown in Figure 1. The area under the peak and peak height with corresponding retention times are shown in Table 2.

Table 1. General phenolic compound tests

\begin{tabular}{ll}
\hline Test & Result \\
\hline $5 \%$ NaOH solution & Soluble \\
$5 \%$ Sodium carbonate solution & Insoluble \\
1\% Ferric chloride solution & Green colour \\
Liebermann reaction & + ve \\
Phthalein reaction & + ve ( red colour) \\
Friedle craft test & +ve ( yellow to orange colour) \\
Bromine decolourisation test & + ve Discharge of reddish - brown colour \\
Baeyer test & +ve disappears of the purple color \\
\hline
\end{tabular}

Table 2. HPLC results for pure extracted and standard resveratrol

\begin{tabular}{ccccc}
\hline Resveratrol & Wavelength, nm & Type isomer & Retention time, min & Peak area \\
\hline Standard & 280 & Cis & 11.700 & 378865 \\
Sample & 280 & Cis & 11.649 & 312922 \\
\hline
\end{tabular}

These results emphasized that even almost all the conditions for extraction and purification occur in dark as much as possible, the substance may be converted from trans configuration to the cis isomer. Although the study focuses on the qualitative specification of the resveratrol and the proper way for its extraction and applications, the steps followed can be assumed for resveratrol quantitative study. 


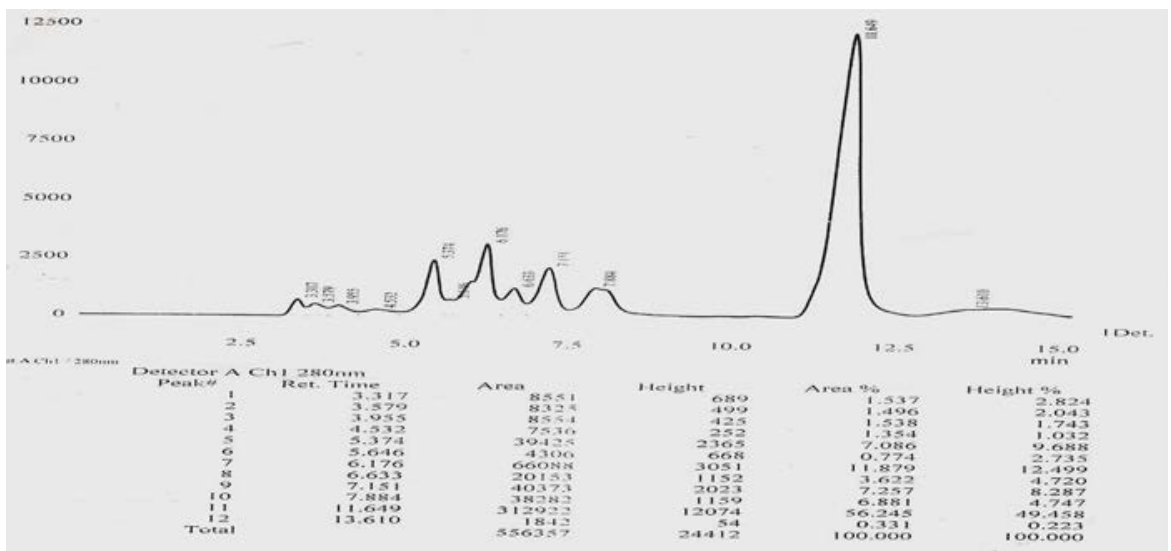

Figure 1. Purified resveratrol standard reading at $280 \mathrm{~nm}$

IR spectra of the resveratrol derivatives are shown in the Figure 2-5 and Table 3.

Table 3. The IR frequencies region for the functional groups of the standard resveratrol and the extracted pure resveratrol.

\begin{tabular}{ccc}
\hline Functional group & $\begin{array}{c}\text { IR Frequencies of } \\
\text { resveratrol standard, } \mathrm{cm}^{-1}\end{array}$ & $\begin{array}{c}\text { IR. Frequencies of extracted } \\
\text { resveratrol }\end{array}$ \\
\hline $\begin{array}{c}\text { Phenolic-OH group } \\
\text { stretching }\end{array}$ & 3294.19 & 3427.62 \\
Aromatic C-H group & 3016.46 & $2928.04-2854.74$ \\
stretching & 1589.23 & 1664.02 \\
Aliphatic C=C & 1149.50 & 1689.70 \\
Aromatic C=C & & \\
\hline
\end{tabular}

Figure 2 shows the infrared spectra for the extracted resveratrol. Derivative $\mathbf{1}$ has many functional groups; $\mathrm{OH}$ broad band group stretching at wavelength 3300-3600, Aromatic C$\mathrm{H}$ group stretching at wavelength 3005.20-2854.74, where aliphatic $\mathrm{C}-\mathrm{H}$ at wavelength 2924-2956, aromatic $\mathrm{C}=\mathrm{C}$ at wavelength1604.83, Aliphatic $\mathrm{C}=\mathrm{C}$ at wavelength1464.02, $\mathrm{C}=\mathrm{O}$ group at wavelength 1735.99 and $\mathrm{C}-\mathrm{O}$ group at 1406.15 .

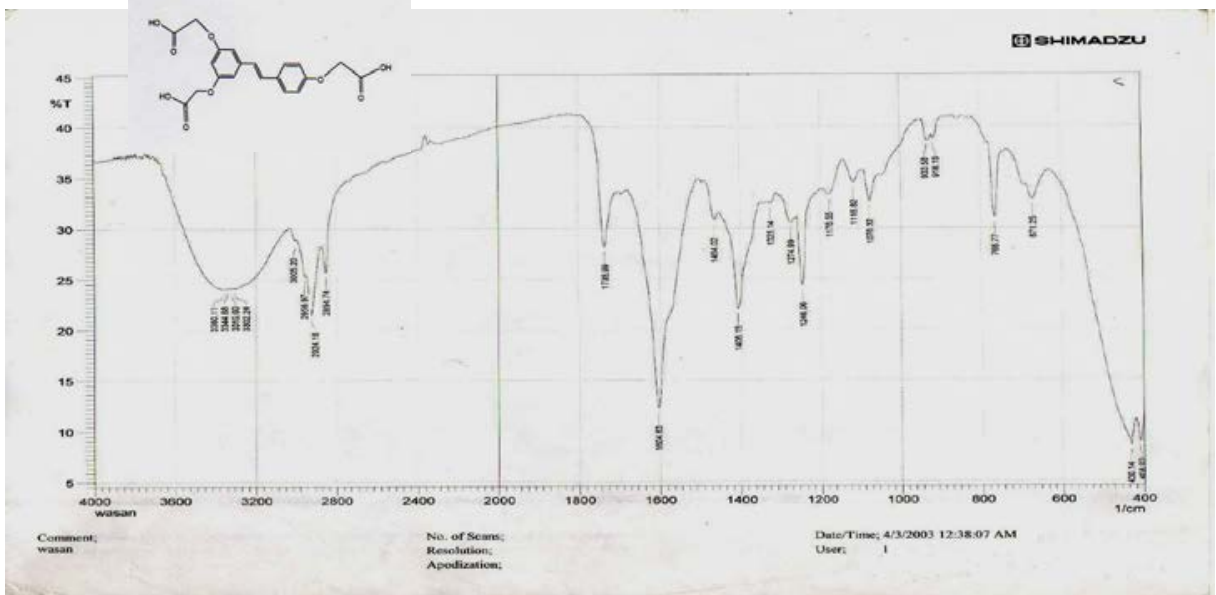

Figure 2. Infrared spectra of derivative 1 
Figure 3 shows the spectra of derivative 2. There are many functional groups stretching are seen. Aromatic $\mathrm{C}-\mathrm{H}$ group stretching at wavelength 3007.12 where aliphatic $\mathrm{C}-\mathrm{H}$ at wavelength 2928.04-28.56.67, aliphatic $\mathrm{C}=\mathrm{C}$ at wavelength $1458.23, \mathrm{C}=\mathrm{O}$ group at wavelength 1716.70 and appearance of $\mathrm{C}-\mathrm{Cl}$ group at 822.49 while disappear of $\mathrm{OH}$ group that mean the reaction is done.

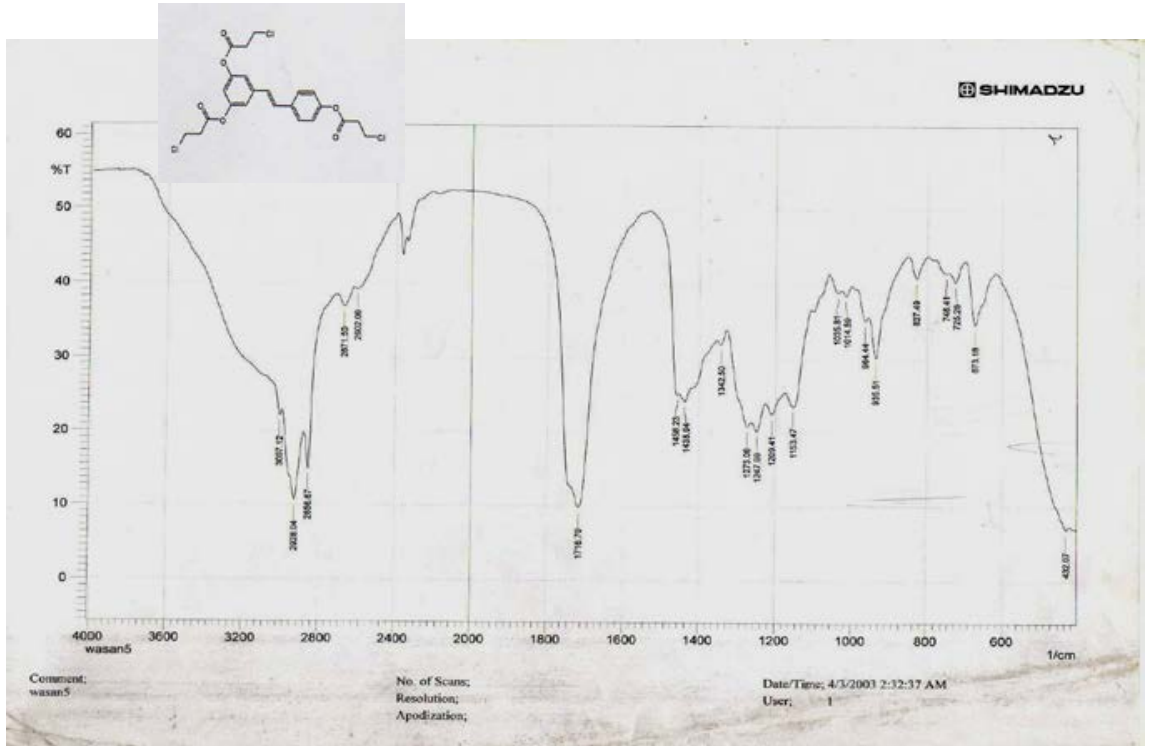

Figure 3. Infrared spectra of derivative 2

Figure 4 shows the infrared spectra of derivative $\mathbf{3}$ has many functional groups; aromatic $\mathrm{C}-\mathrm{H}$ group stretching at wavelength 3005.20 , where aliphatic $\mathrm{C}-\mathrm{H}$ at wavelength 2926.11-2856067, aliphatic $\mathrm{C}=\mathrm{C}$ at wavelength1460.16, $\mathrm{C}=\mathrm{O}$ group at wavelength 1718.63 and disappear of $\mathrm{C}-\mathrm{Cl}$ and appearance of $\mathrm{H}-\mathrm{N}-\mathrm{H}$ group at 3151.79-3254 that mean the reaction is down.

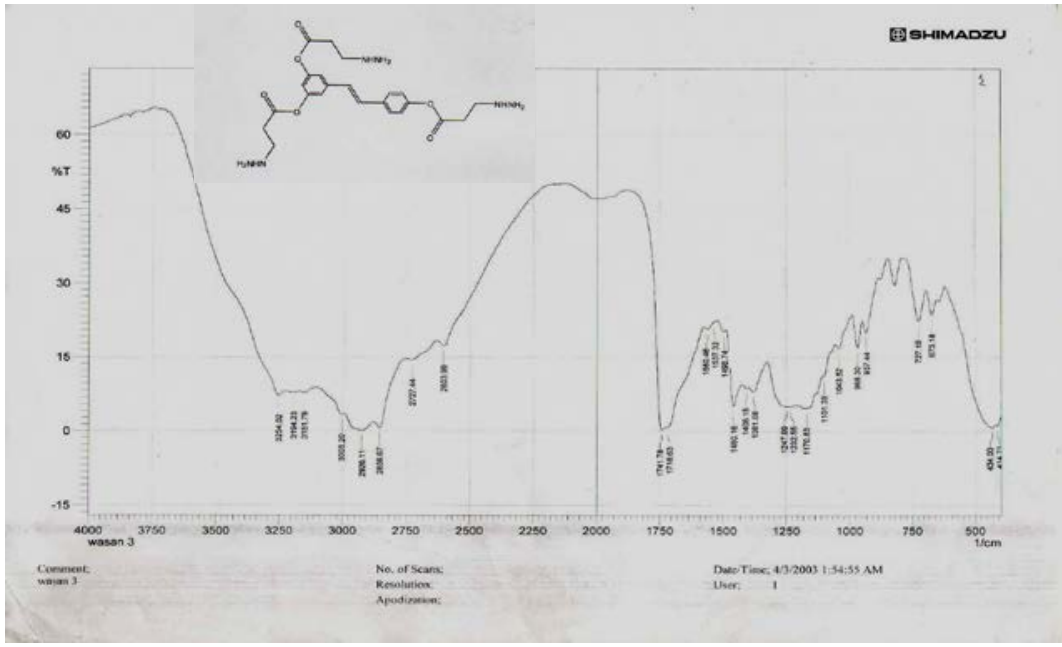

Figure 4. Infrared spectra of derivative 3 
Figure 5 shows the infrared spectra of derivative $\mathbf{4}$ has many functional groups; aromatic C-H group stretching at wavelength 3005.20 , where, aliphatic C-H at wavelength 2928.04, aliphatic $\mathrm{C}=\mathrm{C}$ at wavelength1456.30, $\mathrm{C}=\mathrm{O}$ group at wavelength 1720.56 and disappear of $\mathrm{H}$ $\mathrm{N}-\mathrm{H}$ group while the appearance of three groups C-S group at $752.26, \mathrm{C}=\mathrm{N}$ group at 1602.90 and C-N group at 1246.06.

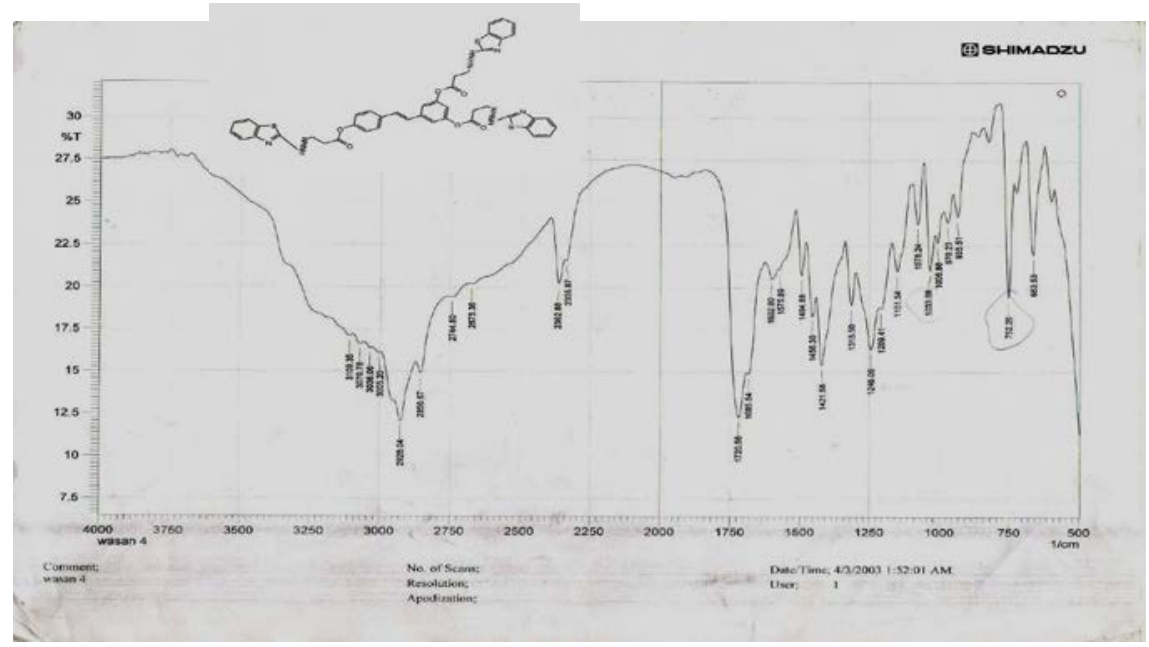

Figure 5. Infrared spectra of derivative 4

\section{References}

1. Budavari S, The Merck Index, $12^{\text {th }}$ Ed., Merck \& Co., Inc. Whitehouse Station, NJ, 1996.

2. Tomas- Barberan F A and Robins R J, Clarendon press- Oxford. New York, 1997.

3. Bass T M, Weinkove D, Houthoofd K, Gems D and Partridge L, Mechanisms of Ageing and Development, 2007, 128(10), 546-52.

4. Elliott P J and Jirousek M, Current Opinion in Investigational Drugs, 2008, 9(4), 371-378. PMID 18393104.

5. Gehm B D, McAndrews J M, Chien P Y and Jameson J L, Proceedings of the National Academy of Sciences of the United States of America, 1997, 94(25), 14138-41143.

6. Trantas E, Panopoulos N and Ververidis F, Metab Eng., 2009, 11(6), 355-366.

7. Canton E C, Garcia V S and Berberan F A, J Agric Food Chem., 2000, 48, 4606-4612.

8. Howitz K T, Bitterman K J, Cohen H Y, Lamming D W, Lavu S, Wood J G, Zipkin R E, Chung P, Kisielewski A, Zhang L L, Scherer B and Sinclair D A, Nature, 2003, 11,191-196.

9. Sharma K K, An introduction to practical Chemistry. New Delhi. India, 1992.

10. Sharma S, Anjaneyulu M, Kulkarni S K and Chopra K, Pharmacology, 2006, 76(2), 69-75.

11. Jeandent P, Meunier P and Bessis R, Vitis, 1994, 33, 183-184.

12. Bavaresco L, Drugs Exp Clin Res., 2003, 29(5-6), 181-187.

13. Baliga M S, Meleth S and Katiyar S K, Photochem Photobiol Sci., 2006, 5, 243- 253.

14. Harborne J B, Chapman and Hall, London, 1984.

15. Romero-Perez A I., Raventor L R and Lacueva C A, J Agric Food Chem., 2000, 49, 201-215.

16. Cannell R L P, Natural Products isolation. Humana press. New Jersey, 1998.

17. Kumler P L, Bates T R, Walter- Perterson H and Servatius T L, Prog Res., 2004, 4, 1-4. 